\title{
Control of Metamorphosis in Lepidoptera
}

\begin{abstract}
T. J. BOUNHIOL has recently published a detailed account of his experiments on this subject, some of which have been published from time to time during the last few years (Bull. Biologique de France et de Belgique, Suppl. 24, 1-199; 1938). Three species of moths were used in this study : the silkworm moth Bombyx mori, the wax moth Galleria mellonella, and the gipsy moth Lymantria dispar in the order of their importance. The paper begins with a description of the life-histories and the methods of rearing. There may be either four or five larval ecdyses in Bombyx mori, but careful measurements of the head diameter will show to which instar the larva in question belongs, and whether it is of the four-or five-moulting type. Equally necessary for the correct interpretation of the later experiments was an examination of the effect on the occurrence of metamorphosis of simple starvation begun at various times after the last larval moult. In the case of Bombyx mori, the larva must be able to feed for at least seven days for metamorphosis to take place. This is liable to be a complicating factor in experiments in which the aim is to inhibit metamorphosis by an operative procedure. For example, the author finds that section of the ven. tral nerve cord prevents metamorphosis if the cut is made before the seventh day after the last larval moult; but this, he suggests, is due merely to an interference with the normal nutrition. The same sort of thing has to be taken into account in con. sidering experiments where regions of a larva are separated off by ligatures with the view of finding their importance in metamorphosis.
\end{abstract}

Perhaps the most interesting part of the work is that dealing with the function of the corpora allata. Dr. Bounhiol describes the delicate surgical method which he has devised for removing these bodies in the larva of Bombyx mori. He finds that loss of both corpora allata in the last larval instar has no effect on the occurrence of pupation; but if, on the other hand, the operation be performed in the instar before the last, then pupation takes the place of the normally ensuing larval moult and a premature metamorphosis is induced. The same is even true of a still earlier instar and in this way a pupa was obtained which weighed a fortieth of the normal.

The result of corpora allata removal in Bombyx mori and the comparable effects following the same operation in the stick insect Dixippus (Pflugfelder, Z. wiss. Zool., 149 ; 1937) are interesting when compared with the results of Wigglesworth on Rhodnius (Quart. J. Micro. Sci., 79 ; 1936). Wigglesworth suggested that the corpora allata secreted a hormone inhibiting metamorphosis and another initiating moulting. In Bombyx the corpora allata possess the first function but apparently not the second.

Dr. Bounhiol also reports that he repeated and confirmed the experiments of Kopec, who found that removal of the cerebral ganglia before a certain critical period prevented metamorphosis. Lastly, he discusses the factors controlling metamorphosis in insects and maintains that the view which most experimenters on this line hold, that pupation is initiated by a hormone circulated by the blood, is still unproved. This must be so until someone makes at least a cell-free extract and induces metamorphosis with it.
E. T. Burtw.

\section{Portable Gas Producers}

$\mathrm{M}^{\mathrm{H}}$ R. BOSWORTH GOLDMAN and Mr. N. Clarke Jones, in a paper presented to the Institute of Fuel on December 8, 1938 (J. Inst. Fuel, 12, 63, February, 1939), pleaded for recognition of the value of portable gas producers as a means of supplying mobile power as an altemative to petroleum. In the event of world petroleum resources becoming exhausted or of their being restricted in times of national emergency, other fuel would have to be used for vehicular propulsion. Producer gas plants are claimed to be between two and three times as efficient as any oil-from-coal process and yet they can utilize the same cheap and easily available home-produced fuel.

The theory of producer gas practice is based on the conversion of carbon into carbon monoxide, which when mixed with further oxygen is combustible in an engine. To achieve this, five units are necessary : a generator, coolers, scrubbers and/or filter, air inlet device and gas throttle. These units are disposed about the vehicle and connected by pipes. They can be fitted to existing vehicles by modification of the existing engine or alternatively incorporated into a specially designed chassis.

A variety of solid fuels, such as anthracite, charcoal, low-temperature coke and peat may be used in these plants, but their efficiency is dependent on factors of reactivity, size and grading, moisture content, ash and volatile content. Actually there are ample resources of suitable fuel available in Great Britain, but their utilization is hampered by the relative difficulty of obtaining supplies as compared with liquid fuels.

As regards performance, figures obtained for certain types of converted vehicles show that for acceleration and hill climbing this type of fuel is but little inferior to petrol. Moreover, it has been proved that maximum power on gas is obtained at a mixture strength slightly weaker than that theoretically required. In the case of petrol, maximum power is only achieved with a richer mixture than is theoretically needed.

For some time past these and other advantages have been fully appreciated on the Continent, and a considerable number of producer gas vehicles are in use. In Great Britain, however, their utilization has been impeded by the Government's refusal to adjust existing regulations in such a way as to place producer gas propelled vehicles on a similar footing to steam and electricity. Co-operation is required between producer gas plant manufacturers, suppliers of the requisite fuel and members of the automobile industry, if this technique is to be developed and full advantage taken of its potentialities as a substitute for liquid fuel. 